\title{
From Physical Analogy to Digital Codification. Digital Turns, Complexity and Disruption
}

\author{
Carlos L. Marcos
}

\section{Abstract}

Drawing has been the most effective way to address architectural representation for centuries. This has allowed for the translation of these plans into built architecture. Based on projections, drawings define a one to one relation between the points of architecture and those cast onto the projection plane. That is to say: an analogy between the three-dimensional object -be it virtual, as in a project, or real, as in the case of the survey- and the drawing that anticipates or represents it, respectively, on the paper. The advent of the so-called digital turns has revolutionized architectural representation in various ways. Firstly, with the creation of the virtual space -a three-dimensional realm- designs came to be modelled instead of drawn. The relation of these models and the actual buildings remained analogical and the point to point correspondence persisted even if, instead of being limited to a bidimensional dominion, the prefiguring representation became three-dimensional too: a virtual model. Being this a substantial change as it may be, the real disruption introduced by computational design has to do with the substitution of analogy through coding. Parametric and algorithmic designs have replaced drawings or models by codes, breaking the visual relation between the designer and the object of his design. This should be credited as the most dramatic change introduced in architectural representation ever.

Keywords

architectural representation, analogy, codification, digital turns, digital disruption.

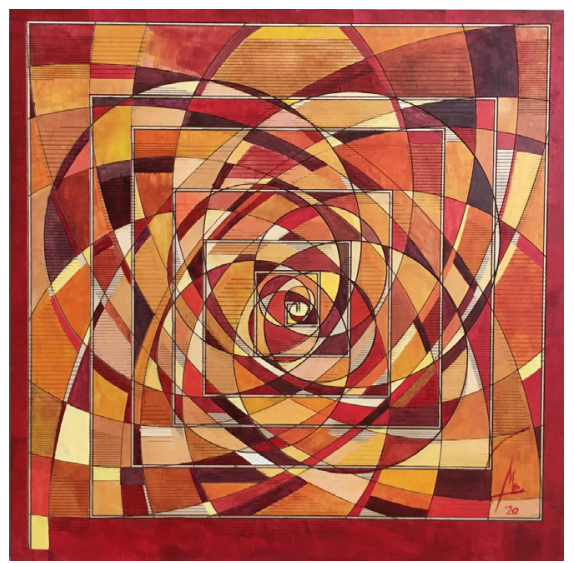




\section{Graphic language. Figuration, projections and accuracy}

Graphic languages follow a very different approach in comparison to the codification of written languages although they have a certain parallelism with pictograms in logographic languages. Graphic language establishes a precise descriptive relationship between that which is being represented and the representation itself through resemblance. In fact, any figurative attempt to depict what is seen is based on analogy, not on codification [Deleuze 2007] despite the fact that there certainly is some codification in every graphical representation, something to which Nelson Goodman [Goodman 1976, p. 22I] has referred to as 'notational' regarding architecture and its graphic representation systems.

This analogical representation is the reason why we can understand and read cave drawings done by the first human beings although we are unable to read cuneiform inscriptions done only 4000 years ago. We do not need to know a particular coding to understand the drawings because they are based on analogic 'resemblance', but we do need to know the codes of Sumerograms to decipher the meaning as they are based on 'codification'.

A child of a small age could draw a human figure but would be unable to produce a realistic image of it. However, it is interesting to note that he would depict every distinctive part that constitutes the formal elements of the human figure: he would not add or supress any of the limbs, hands, feet, head or body even though the proportions would be unrealistic. This consistency of the relation of the parts to the whole that figuration mirrors with regard to its referents was already mentioned by Ugo Volli within the interesting semiotic debate of the last third of the twentieth century [Rabasa 2018, p. 154]. We prefer to consider it as a 'topologically' consistent representation of the figure, not a geometrical one [I]. The drawn figure would resemble the original although this similitude might be inaccurate.

Proper 'geometric' representation is based on projections. The relationship of analogy between the object and its representation is perfectly accurate and follows a precisely established procedure. As we find it marvellously depicted in Albrecht Dürer's etching The Draughtsman of the Lute (fig. I), for every point of the real lute we find a correspondence with a cast point

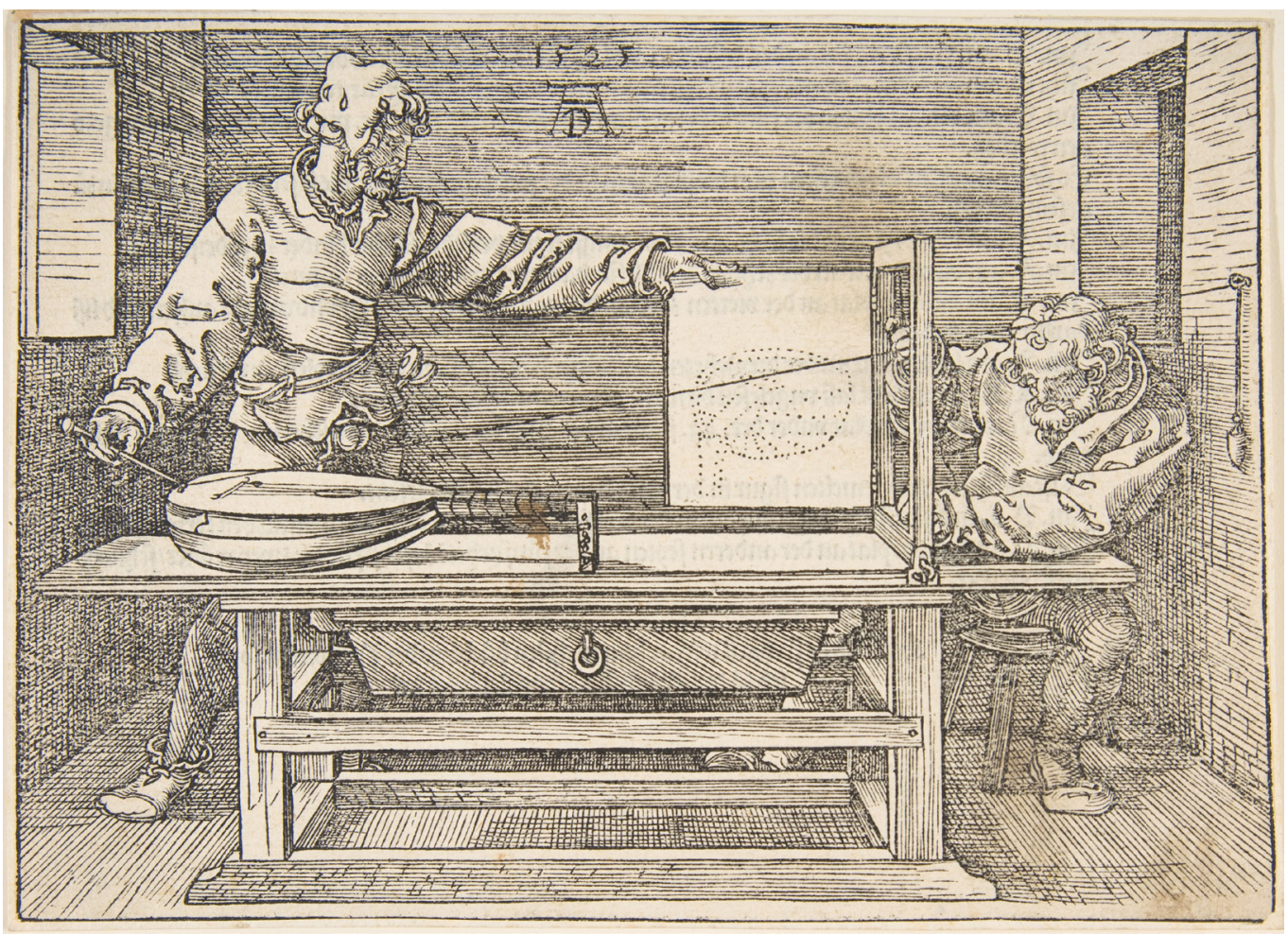


on the paper of the drawn lute. If done with perfect accuracy we would thus obtain a precise projection on the paper: the drawing is no longer an approximate depiction of the object but an accurate representation where no margin of error is allowed, guaranteeing a perfect geometrical resemblance and a perfect geometric analogy. However, this drawing machine devised by Dürer is limited to producing conical projections or 'perspectives'. The point of view that appears in the etching is placed on the hook nailed to the wall.

\section{Architectural representation, plans and translations}

Drawings are extraordinarily precise in the description of material objects, that is to say, particulars. Words, on the contrary, having being conceived for the generic representation of beings, completely lack the ability to specify the particularities and subtleties we find in every material object. That is because words are based on the assumption of universals [Marcos 2010, p. 265]. Architects and engineers alike have dedicated their endeavours to the representation of their projects through drawings ever since they learned to properly use projections for this reason.
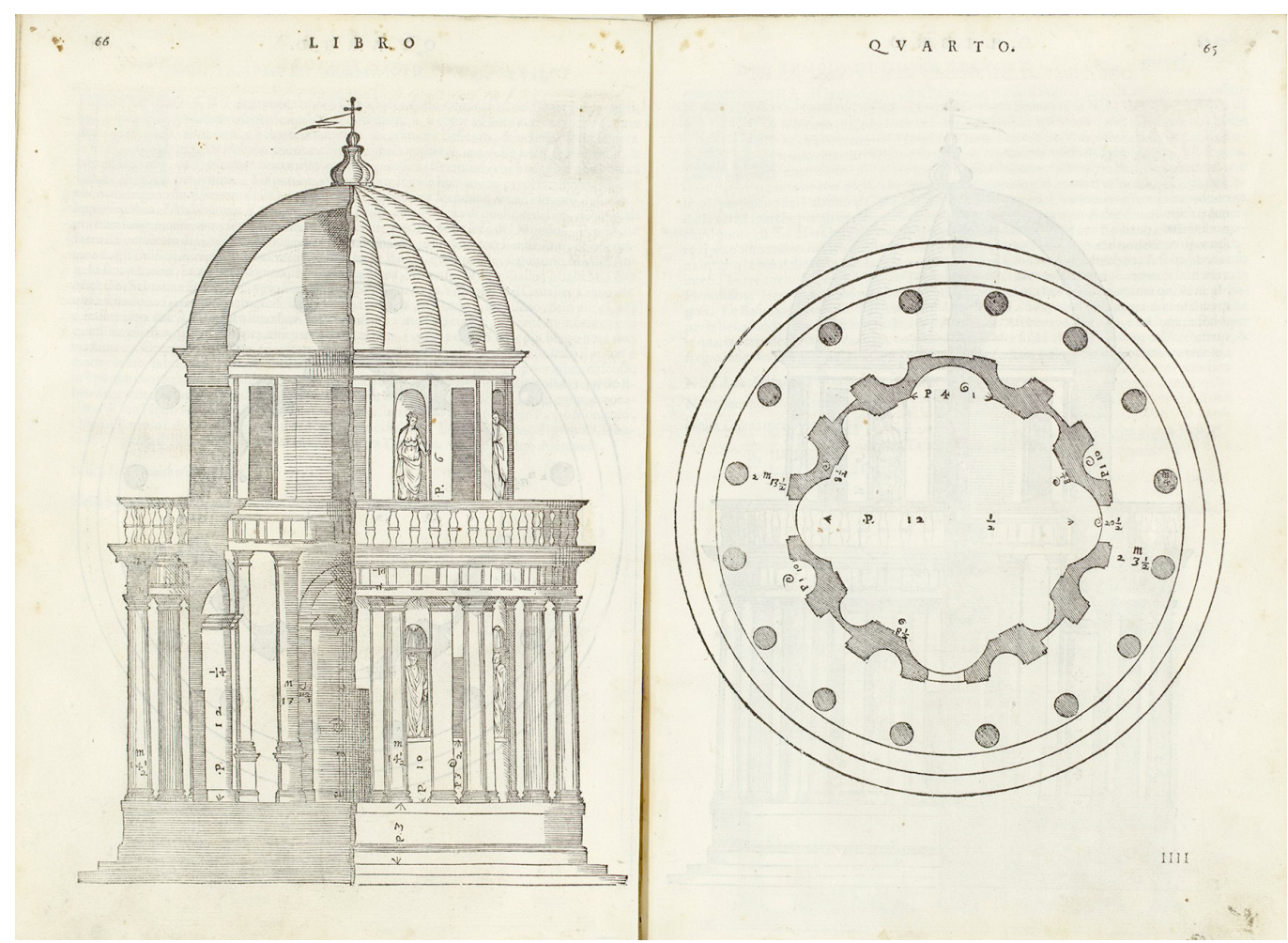

As early as in 1485 does Alberti in his Re Aedificatoria prompt architects to use parallel projections in the representation of their work relegating the use of perspective for painters (Alberti 199I, p. 95). Even considering the fact that the precise definition of projections can probably first be found in Desargues and that the theoretical development for Descriptive Geometry would have to wait until Gaspard Monge's systematisation, it is no less certain that Renaissance architects were able to draw floorplans, sections and elevations precisely according to the principles of parallel projection (fig. 2). In fact, we have evidence that this architectural canon of representation was set as early as 1519 through a famous letter of Raphael to Pope Leo X [Hart, Hicks 2006]. 
Fig. 3. The visitation of St. Elizatbeth, Geronimo Nadal, Adnotationes et meditationes in Evangelia, Antwerp, 1595 (left), The visitation of St. Elizatbeth [drawn in accordance with Chinese perspectival style], Giovani de la Rocha, Metodo del Rosario, 1620 (right)
Alberti was clear about achieving plans with true dimensions in order to ponder true proportions avoiding the deceitful foreshortenings of perspective. Arnheim has pointed out that both systems, based on projections, are simply different and, therefore, attain dissimilar results but neither is, in principle, more truthful or deceitful [Arnheim 2005, p. I25, I26]. Regarding proportions and measures, parallel projection is more accurate; regarding visual appearance, perspective is more adequate. Moreover, both systems have cultural implications that we have grown accustomed to interpret. Panofsky [Panofsky 20 I 2] made a strong argument to consider perspective as a symbolic form and not just the result of applying a geometric procedure. Probably the confrontation of these undetachable cultural values of both systems can be best understood considering the reaction of Chinese with regard to perspectival representations introduced by Jesuits missionaries (fig. 3). The latter had to 'redraw' to 'Chinese perspective' -axonometric representation [2]- sacred scenes so that they could meaningfully convey the message for the Chinese [Scolari 2012]. What we give for granted when we see a painting within our western culture is not as universal as might have been thought.
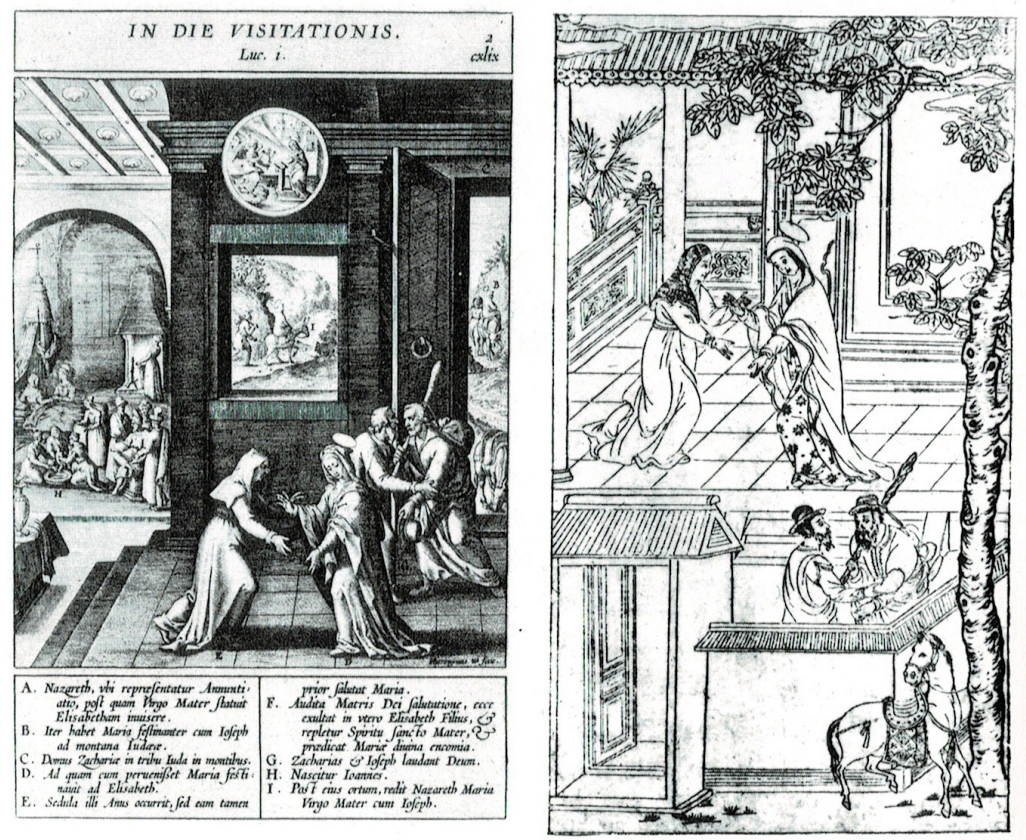

In terms of design Alberti was more preoccupied with representing the being rather than the appearance. Therefore, a more abstract way of representation was needed and certainly parallel projections, with an elusive point of view in the infinite, implied a more abstract approach. In 1908 Worringer already associated naturalism with figuration and with mimesis while he related abstraction with the conceptualization of reality and the search for the universal [Worringer 1966].

Above all, Alberti was concerned to achieve a system of representation that could unmistakably convey to third parties accurately how and what to be built. He was very responsible for the way in which these documents would constitute a clear and complete set of plans: the project as we know it [Carpo 20 I I, p. 20,2 I]. Drawings by architects would become to be considered ever since as the result of an intellectual endeavour and the only work truly accountable for their authorship. Thus, they no longer needed to be involved into the construction process itself as the master builders in the middle ages were. From then onwards and up until the advent of the so-called digital turns [Carpo 2012; Carpo 2017], the plans where what architects ought to do for others to materialise the construction process [3]. 


\section{Digital turns and representational shifts}

The advent of digital tools in architecture drastically changed the way in which architects represented architecture. Just as it happened during the Renaissance, this major shift ultimately affected the way in which they conceived their designs and, because of it, architectural language itself. However, this didn't happen just by chance.

Apart from the obvious differences of drawing manually or aided by a computer [4], the very first significant disruption introduced by computers was the invention of a three-dimensional virtual space and, consequently, the replacement of drawing by 3D modelling. The substantial conceptual shift was the fact that projections were, in principle, no longer needed. With the advent of this virtually 'scaleless' cyberspace, 3D models could dwell in this three-dimensional alterity alien to the physical world [5] yet with the accuracy of drawings or beyond it.

Even considering the fact that decades after the advent of information technologies computer plans continued to be elaborated -and currently continue to do so, we will come to that later- the next step in this deep representation transformation introduced by computers are renderings and perspective line drawings generated from 3D models. And this is really interesting from a geometric point of view as it metaphorically closes the circle or modifies the directionality of projections. Evans suggested that the representation of architecture through projections in architectural drawings implied a directionality of the projection rays [Evans 1989]. Either drawings are translated into buildings according to the project's plans -from virtual existence to physical construction- or, in the case of survey plans, reversing such process so that these plans represent already existing buildings (fig. 2) -from built architecture to graphic representation-. In both cases, the projections and the analogical point to point relationship between these drawings and architecture is ideal or virtual. In other words, excepting the use of literally projective devices such as Dürer's mentioned drawing machine, this projection lines that bind real points in space and the points in the drawing are only theoretical assumptions that the draughtsman has in mind when producing the drawing and establishing this analogical relationship.

However, the nature of virtual 3D models and the possibility to cast their geometries on a plane to generate a drawing drastically changes this projective relationship as computer en-

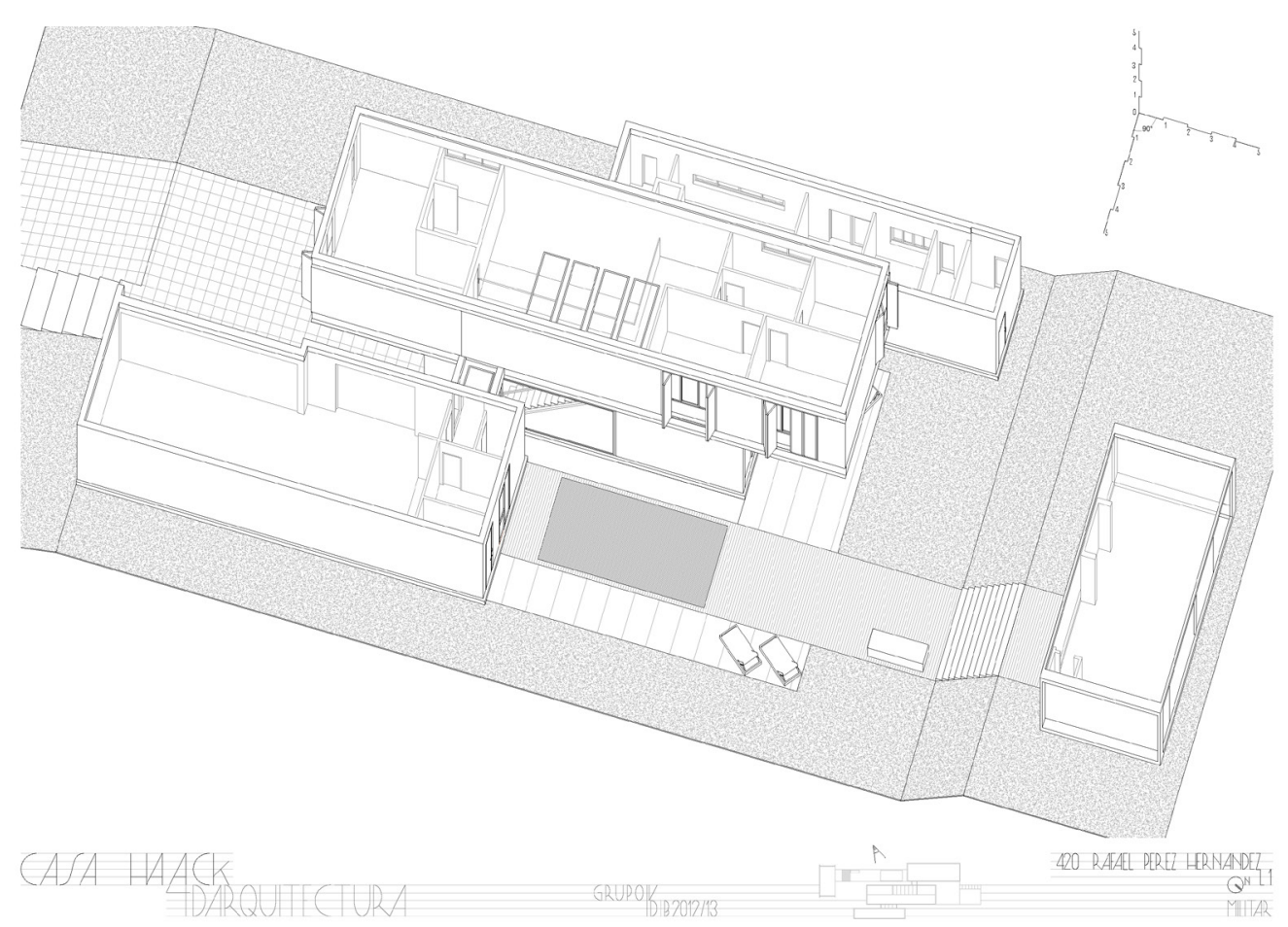


gendered projections remain within the virtual space. Thus, the 3D model and the flatshots or 2D drawings [6] are virtual but the projection is really established between the different sets of points in the virtual space: no imagination anticipating or reversing the process between dimensions is longer needed.

Once this was a real possibility [7], architects, who, in the majority of the cases, still need to produce plans to convey their designs to third parties for construction, began to use 3D models to produce plans [8]. Obviously, these projections could be either parallel or conical to produce axonometric projections or perspectives, respectively. As computer programmers defined the projection direction as a perpendicular to the projection plane -the general case- oblique axonometric drawings (fig. 4) need to be obtained following indirect methods such as the ones described, for example, by Cabezos and Cisneros [Cabezos, Cisneros 20 I0] or Franco Tabaoda [Tabaoda 20 I I, pp. 70-72].

Additionally, computers may also produce images or renderings. Images and drawings share their bidimensional graphic nature but images, unlike drawings, which are constituted by lines and points, spread over the whole plane. Linear computer drawings are defined by vectors which allow to scale them up or down unlimitedly. Digital images, on the contrary, are made up of pixels -really small square units or image tesseras- which imply a given resolution or pixel density and an initial image size; this discretization does not allow such scalability without a loss of information.

From a graphic narrative point of view, the generation of images has allowed to produce hyperrealist infographic renderings in unprecedented ways. Proficiently using photomontage techniques, unbuilt architecture can now be visually anticipated and contextualised. The level of sophistication in the representation of visual appearance has reached such perfection that we doubt whether they are computer images or photographs of real architecture [Llopis 20 I8].

\section{New geometries born from nowhere}

What began as a repertory of enhanced representational and design possibilities developed into a much greater potential, transcending the former role that representation and ideation had within the architectural discipline.

These new possibilities unfolded by the conscious use of digital tools have emerged in the past three decades defying the architectural canon set by modernism (fig. 5). Complexity as a result of improved computer design capabilities was introduced in architecture but certainly not as a result of a discourse based on contradiction [9]. Postmodernism, in the case of deconstruction, could be seen as the emergent new aesthetics which were, to a certain extent, digitally stirred. However, if we were to follow the amazing variety of architectural forms that have emerged thanks to the use of computers ever since, a new digitally borne aesthetics must be acknowledged [10].

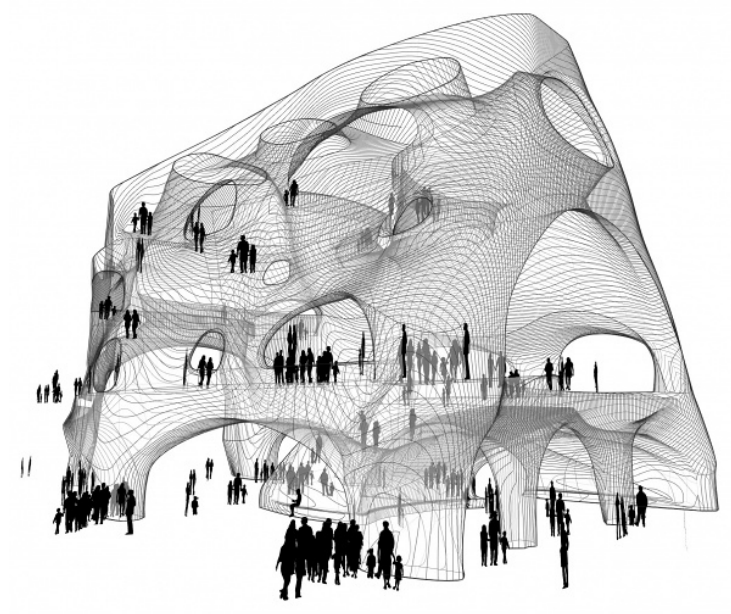




\section{Codification of form}

The most disruptive architectural change brought by computers is a step beyond geometrical representation and analogy to define it in terms of codification: scripts instead of drawings. Parametric and algorithmic designs have introduced a real shift of paradigm in architecture. Geometries are no longer defined analogically: they are encoded and written in computer scripts and formulas, something that could be referred to as "open form" [Marcos 20 I0]. Architects of the twenty first century are expected to program, instead of drawing or modelling, their designs. Thus, the analogical relationship is lost and a mathematical codification of form emerges, leading to unprecedented levels of geometric complexity.

This new stage is what Carpo [Carpo 2017] has referred to as the second digital turn, where truly computational design operates mediating with big data within the design itself. Form-finding strategies have completely altered the relation of the designer towards the object of his design. Although running a script to find the best solution implies taking advantage of this redefinition of geometry as a coded formal structure and the 'development' of the algorithm is authored by the architect-programmer, the computer plays the role of a 'virtual draughtsman' that, benefiting from its extraordinary computerization potential, arrives to an optimal design [ I I]. Zaha Architects' structural exoskeleton and the voided shape design of the prism for the Morpheus Hotel in Macau, for instance, was optimised considering the recurrent typhoons in the geographical location. Neither the triangulation of the exoskeleton or the perforations on the tower are alien to such dynamic forces; they are, in fact, the result of such performance-based design (fig. 6). Voxels -a sort of volumetric pixels or digital bricks- have recently become a tool to improve the design through simulation, for instance, in terms of structural performance or acoustical optimization, also contributing to achieve a physical visualization of data that might be relevant for the design itself [Lanzara 20/9].

Fig. 6. Rendering and photomontage. Morpheus hotel in Macau, Zaha Hadid Architects, 2013-20I8 (courtesy of Zaha Hadid Architects).

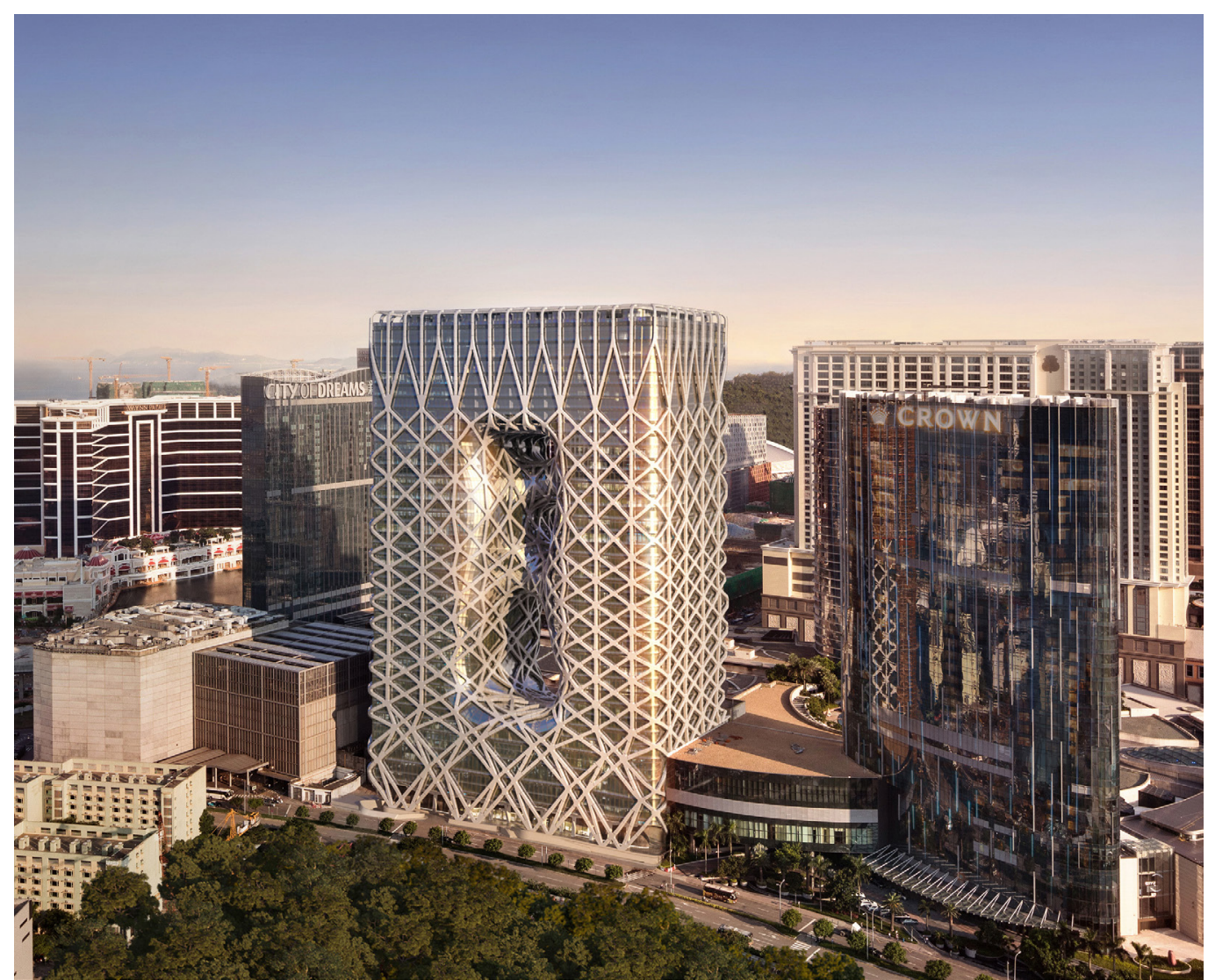




\section{Conclusions}

Architectural representation belongs to the realm of graphic languages. Although some as Goodman have referred to architecture as an allographic discipline -architects make drawings, not buildings-, graphic representation strictly based on projections may not have a status really equivalent to musical scores and music: these are codified, whereas architectural drawings, even if codification is also part of its representation system, are primarily founded on precise geometrical analogy.

This clearly distinguishes architectural representation as a language from any other language. What architects define through drawings are signifiers, not meanings. Drawings are architecture themselves and not signs that represent or convey a meaning other than built architecture.

Digital tools have deeply changed the ways architects represent architecture through the introduction of the virtual space and the possibility to work directly with 3D models. These, in turn, use the possibility to return to drawings as cast projections.

Ultimately, the introduction computational architecture has introduced a new disruptive twist as geometries are coded into scripts losing the analogical characteristic relationship between the architect and his design.

\section{Notes}

[I] Anyone could imagine it represents a human figure even if these mistakes make of it a disproportionate representation of the original because the parts and the connectivity of them to the whole would still remain.

[2] These Chinese axonometric early representations as well as French cavalier projections starting in the sixteenth century did not probably use the correct reduction in the third axis due to the projective foreshortening dependent on the direction in which to generate the projection but they certainly conveyed the architecture they represented in an efficient way consistently maintaining the parallelism principle characteristic of parallel projections.

[3] Architects, from then onwards, remained more or less alien to the construction of architecture as according to Alberti it should be considered the builders' solely responsibility. To a certain extent, the Beaux Arts conception of the profession -which is connected to the idea of the architects as merely designers and which has been very influential within anglo-saxon culture countries- is an extension of this conception, in contrast with the Ecole Polytechnique approach.

[4] The cover figure of this text corresponds to Prime number series I. [2, I03] (mixed media) I have been working on exploring the possibilities of hybrid approaches between the digital and the physical. The painting is in fact an analogue-digital hybrid that has been drawn in Autocad, digitally printed with a laser cutter on plywood and hand painted with acrylic based on the prime number's progression from 2 to 103 . The scale of the 'design' was fixed so that it would fit a $40 \times 40 \mathrm{~cm}$. plywood piece. Drawing with our eyes on the screen and our fingertips on the computer mouse instead of drawing with our hands and a pencil on a real paper at a given scale establishes a further distancing between our conception and its visualization, and regarding the amount of information to a specific graphical scale.

[5] Though architectural physical models had been a common practice in the profession for many centuries their accuracy was inevitably limited by the material employed, the craftsman's ability as well as the reduction of the scale and, consequently, of the information they could embody.

[6] To mention the commands in Autocad or Rhino to obtain this projections from the 3D model.

[7] Due to extension limitations we are not dealing here with the novelties and implications that BIM has introduced with regard to representation, including some of the very interesting visualization enhancements that the increased complexity of the modelisation require. Apart from the additional step within the history of information technologies introduced by the geometrically referenced data base structure of the files, from a representational or projective point of view, BIM hasn't significantly altered things.

[8] Even if these had to be post-produced at a later stage in the graphic process to add codification such as lineweights or even extra-graphic notational information.

[9] Although computers's inherent outstanding computerization capabilities have often mislead architects towards a banalization of form, complexity is not only the result of technology but it is also part of a new cultural discourse which has developed parallel to the digital turns.

[10] A rich -and often whimsical, we may add-formal realm has been produced out of nowhere as it is no longer indebted to any other disciplinary avant-gardes: architecture can boast of having spurred a new avant-garde digitally borne.

[I I] Its worthy to note that the intelligence in this computational approach is the result of a human conception while writing a script. Additionally, architects must still critically analyse the different design versions of the generated digital typology to choose the best. 


\section{Acknowledgements}

This paper shows some of the results of the research undertaken at UNCC during a sabbatical leave by the author, partially funded by the University of Alicante, Conselleria de Educación, Cultura y Deporte, Generalitat Valenciana.

\section{References}

Alberti Leon Battista (199|). De Re Aedificatoria. Madrid: Akal.

Arnheim Rudolf (2005). Arte y percepción visual. Barcelona: Gustavo Gili.

Cabezos Bernal Pedro M., Cisneros Vivó Juan (2010). Obtaining Oblique Perspectives from Three-Dimensional Models. In Revista EGA. Expresión Gráfica Arquitectónica, 16, 2010, pp. 82-87.

Carpo Mario (20 I I). The Alphabet and the Algorithm. Cambridge, Massachusetts:The MIT Press.

Carpo Mario (ed.). (2013). The Digital Turn in Architecture. Chichester: John Wiley \& Sons.

Carpo Mario (2017). The Second Digital Turn: Design Beyond Intelligence. Cambridge (Mass.):The MIT Press.

Deleuze Gilles (2007). Pintura. El concepto de diagrama. Buenos Aires: Ed. Cactus.

Evans Robin (1997). Translations from drawing to building. In Evans Robin. Translations from drawing to building and Other Essays. Cambridge (Mass.): MIT Press.

Evans Robin (1989). Architectural Projection. In Blau Eve, Kaufman Edward (ed.). Architecture and its image: four centuries of architectural representation. Montreal: Canadian Centre for Architecture.

Franco Taboada José Antonio (20II). Geometría Descriptiva para la representación arquitectónica. Santiago de Compostela: Andavira Editora S. L.

Goodman Nelson (1973). Languages of Art. An Approach to a Theory of the Symbols. Indeanapolis: Hackett Publishing.

Hew Soonhin (2012). Using Combining Evolution of Pictogram Chinese Characters to Represent Ideogrammic Compounds Chinese Characters. In 7th International Conference on Computing and Convergence Technology (ICCCT) Proceedings. Seoul: Curran Associates, pp. $219-223$.

Hart Vaughan, Hicks Peter (2006). The letter to Leo X by Raphael and Baldassare Castiglione, c. I 5 I 9. In Vaughan Hart, Hicks (eds.). Palladio's Rome: A Translation of Andrea Palladio's Two Guidebooks to Rome. New Haven:Yale University Press.

Lanzara Emanuela (2019). From Pixel to Voxel. Architecture Between Liquid Identity and Physical Image. In Revista EGA. Expresión Gráfica Arquitectónica, 24(36), 2019, pp. 232-245.

Llopis Jorge (20 I 8). El paradigma fotográfico del dibujo arquitectónico digital. In Arte, Individuo y Sociedad 30 (3), 20 I8, pp. $557-573$

Marcos Carlos L. (20I0). Anatomía del pensamiento gráfico. Figuración, representación, abstracción e ideación. In Actas XIII Congreso Internacional de Expresión Gráfica Arquitectónica. Valencia: Universidad Politécnica de Valencia, pp. 263-268.

Marcos Carlos L. (20I0). Complexity, Digital Consciousness and Open Form: A New Design Paradigm. In LIFE IN:formation ACADIA 2010 Proceedings, New York, pp. 81-88.

Panofsky Erwin (2012). Persepctive as a Symbolic Form. New York: Zone Books.

Rabasa Enrique (20 I 8). Ikognosie: Reflections on the philosophical thinking about the nature of representation through images In Revista EGA. Expresión Gráfica Arquitectónica, 23(34), 2018, pp. I48- 157.

Scolari Massimo (2012). Oblique Drawing. Cambridge, Massachusetts:The MIT Press.

Worringer Wilhelm (1997). Abstracción y naturaleza. Méjico: Ed. Fondo de Cultura Económica.

\section{Author}

Carlos L.Marcos, Universidad de Alicante, carlos.marcos@ua.es

To cite this chapter: Marcos Carlos L. (2020). From physical analogy to digital codification. Digital turns, complexity and disruption. In Arena A. Arena M., Brandolino R.G., Colistra D., Ginex G., Mediati D., Nucifora S., Raffa P. (a cura di). Connettere. Un disegno per annodare e tessere. Atti del $42^{\circ}$ Convegno Internazionale dei Docenti delle Discipline della Rappresentazione/Connecting. Drawing for weaving relationships. Proceedings of the 42 th International Conference of Representation Disciplines Teachers. Milano: FrancoAngeli, pp. 599-607. 